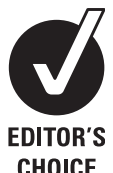

CHOICE

\title{
Predictive genetic testing in minors for late-onset conditions: a chronological and analytical review of the ethical arguments
}

\author{
Cara Mand, ${ }^{1,2}$ Lynn Gillam, ${ }^{3,4}$ Martin B Delatycki, ${ }^{1}$ Rony E Duncan ${ }^{5,6,7}$
}

${ }^{1}$ Bruce Lefroy Centre for Genetic Health Research, Murdoch Childrens Research Institute, Melbourne, Victoria, Australia "Monash University, Clayton, Victoria, Australia ${ }^{3}$ Children's Bioethics Centre, Royal Children's Hospital, Melbourne, Victoria, Australia ${ }^{4}$ School of Population Health, The University of Melbourne, Victoria, Austraila

${ }^{5}$ The Centre for Adolescent Health, Royal Children's Hospital, Melbourne, Victoria, Australia

${ }^{6}$ Murdoch Childrens Research Institute, Melbourne, Victoria, Australia

${ }^{7}$ Department of Paediatrics, The University of Melbourne, Victoria, Australia

Correspondence to Dr Rony Duncan, The Centre for Adolescent Health, Royal Children's Hospital, 3052. Melbourne, Victoria, Australia; rony.duncan@mcri.edu.au

Received 17 June 2011 Revised 18 December 2011 Accepted 7 February 2012 Published Online First

8 March 2012

\section{ABSTRACT}

Predictive genetic testing is now routinely offered to asymptomatic adults at risk for genetic disease. However, testing of minors at risk for adult-onset conditions, where no treatment or preventive intervention exists, has evoked greater controversy and inspired a debate spanning two decades. This review aims to provide a detailed longitudinal analysis and concludes by examining the debate's current status and prospects for the future. Fifty-three relevant theoretical papers published between 1990 and December 2010 were identified, and interpretative content analysis was employed to catalogue discrete arguments within these papers. Novel conclusions were drawn from this review. While the debate's first voices were raised in opposition of testing and their arguments have retained currency over many years, arguments in favour of testing, which appeared sporadically at first, have gained momentum more recently. Most arguments on both sides are testable empirical claims, so far untested, rather than abstract ethical or philosophical positions. The dispute, therein, lies not so much in whether minors should be permitted to access predictive genetic testing but whether these empirical claims on the relative benefits or harms of testing should be assessed.

\section{INTRODUCTION}

Predictive genetic testing, offered alongside indepth counselling, has established itself as an accepted component of care for adults at risk of developing a late-onset genetic condition. Similarly, there is broad support for the provision of predictive testing for conditions, which manifest in childhood or adolescence, especially where there are effective interventions available during this time (eg, familial adenomatous polyposis (FAP) coli). Conversely, there is considerable controversy associated with offering these tests to minors for conditions, which rarely manifest prior to adulthood. This paper investigates this controversy.

Dispute arises when testing outcomes cannot clearly provide a benefit for the minor. Canadian investigators Bloch and Hayden, in a 1990 editorial in response to requests to perform predictive tests in minors for Huntington's disease (HD), argued that access to predictive genetic testing should be restricted to those $\geq 18$ years of age. ${ }^{1}$ The debate that ensued highlighted the need for guidelines to assist the practice of clinicians worldwide. In the same year as Bloch and Hayden's seminal publication, the International Huntington Association together with the World Federation of Neurology entered the debate with the publication of the first policy statement addressing this newly controversial area. ${ }^{2}$ Subsequent years saw the publication of several more guidelines and recommendations relating to predictive testing in minors. In 2006, a systematic review of all guidelines and policy statements concerning the predictive and presymptomatic testing of minors was undertaken. ${ }^{3}$ Despite the subtle differences in the published statements, policies and guidelines, they agree in recommending against testing in minors where there is no medical benefit in the immediate future, as Borry et al discuss in their systematic review ${ }^{3}$ :

'It is clear that the availability of medical benefit is the most important justification to perform predictive and presymptomatic genetic testing in minors, regardless of the onset of the disease. The absence of medical benefit is the most important justification to defer testing until the adolescent or adult is able to make a personal decision on this matter after a full discussion and exploration of the issues.'

Almost two decades since the publication of the first guidelines concerning predictive testing in minors, considerable disagreement still exists in the literature. Opponents of testing highlight potential harms, while proponents look to testing as an opportunity to promote benefit, with each side drawing upon fundamental ethical principles to support their diametrically opposed positions. The evolution of this ethical discourse over the past 20 years, with its various arguments for and against testing, has not so far been tracked and analysed. This review aims to fill that gap, by providing a detailed chronology and mapping of how the arguments entered the discourse and developed over the years. This mapping will offer an opportunity for the debate to advance by making clear where the key points of disagreement lie.

This review is not simply a catalogue of the arguments for and against testing in minors, but rather an analysis of the longitudinal evolution of the debate, highlighting the relative emphasis given to certain arguments. This review provides a new framework for understanding the debate, bringing to the surface untested claims and highlighting the opportunities for empirical research. 


\section{METHODS}

\section{Data collection}

A comprehensive review of the literature on predictive testing in minors for late-onset conditions was performed. Bloch and Hayden's 1990 publication ${ }^{1}$ is the earliest significant entry in the debate and, for the purpose of the literature search, was taken as the starting point. The search included publications up to December 2010. The search was limited to publications in English and a subset of medical databases. Searches were performed using the databases PubMed, Medline, Web of Science, PsychInfo and CINAHL. Initial keywords were: child OR childhood OR minor OR adolescen*; predictive OR presymptomatic OR susceptibility OR predispositional; adult onset; genetic test*; Huntington* and BRCA*. A secondary manual search was directed by selected citations in the published literature.

Inclusion criteria were articles published in peer-reviewed journals and concerned primarily with the predictive genetic testing of minors (under the age of 18 years) for adult-onset conditions for which testing provides no immediate medical benefit (eg, HD and familial cancers associated with BRCA mutations). Only articles that substantively addressed this issue were included. Exclusion criteria included articles that were predominantly concerned with carrier testing in minors (eg, gene testing to identify Tay Sachs disease heterozygotes) or testing of conditions for which medical intervention commences prior to adulthood (eg, FAP). Guidelines and policy statements were also excluded, as there is already published work summarising these recommendations. ${ }^{3}$ Empirical studies, including systematic reviews, were also excluded on the basis that this review aimed to survey the normative opinion-driven contributions, which make claims regarding ethically best practice. A total of 53 papers satisfied the inclusion criteria and were included in this review.

\section{Data analysis}

Interpretative content analysis ${ }^{4}$ was used to identify and catalogue discrete arguments presented for and against predictive testing of minors for late-onset conditions. Arguments were catalogued, regardless of whether the authors were putting forward their own personal views or were citing other authors' arguments to review past literature. Papers were also included if they referred to the relevant argument, regardless of the author's judgement on the worth of that argument. In this way, a true chronology of the arguments was developed, documenting new arguments as they arose and the way in which existing arguments gained strength in the literature through multiple further citations. These arguments were then grouped according to whether they supported or opposed predictive genetic testing in minors and then subgrouped according to the content of the argument. The process of coding and allocating arguments to appropriate groups was performed by all authors and discussed within the team until consensus was achieved. This data is presented in box 1, linking each argument with the paper(s) in which it was referenced, with the total number of times each argument has arisen in the literature recorded. Beside the description for each argument is a label listing the year the argument first appeared in the literature, the year it was most recently mentioned and the cumulative number of times the argument has appeared during that period. For example, an argument labelled '1990-2008:26' appeared first in 1990, was last referred to in 2008 and has appeared in a total of 26 papers. Figure 1 presents this information visually.

\section{RESULTS}

Of the 33 discrete arguments identified, 16 opposed and 17 supported predictive genetic testing in minors. The arguments were subsequently grouped according to 10 thematic categories, four against $(1 \mathrm{~A}-1 \mathrm{D})$ and five in favour $(2 \mathrm{~A}-2 \mathrm{E})$ of testing. The arguments and categories are presented in box 1 and the following discussion uses this framework.

\section{DISCUSSION}

The battlefield was set in the period 1990-1994, with eight separate publications regarding predictive genetic testing in minors. At the beginning of the ethical debate, authors promoted a conservative approach, arguing against testing for minors. Eight distinct arguments against predictive testing came to light in the very first year. Indeed, the case against testing was largely established by 1994, and these initial arguments against testing appeared repeatedly in the following years. By contrast, momentum in favour of testing evolved more slowly, with most arguments beginning to surface in the mid-to-late 1990s. Beyond this broad commentary on the 'shape' of the discourse thus far, there is no obvious pattern.

Certain arguments are more frequently cited in the literature than others (1A.1, 1B.1, 1C.1-1C.3, 1D.1, 1D.2, 2A.1 and 2C.1). There are a number of considerations that come to bear in examining the relative frequency of each of the arguments. The prominence of an argument, in terms of the number of times it appears, provides an element of insight into the level of importance attributed to it by commentators. Repetition in these terms, though, does not necessarily connote a strong or even sound argument. Clarke ${ }^{47}$ points to this trap in noting that it is insufficient to, 'look at the length of the two, rather arbitrary, lists of arguments and then come to the unwarranted conclusion that the two opposed sets are of equal force'. An argument is not intrinsically significant simply because it has appeared in the literature. It must be tested against opposing positions. That said, there is some value in a tally, to understand what authors to date have considered important.

In the last 5 years all but one (1A.6) argument has continued to appear, highlighting that the debate is ongoing, with little resolution. The debate, such as it is, has adopted a to-and-fro pattern defined by parallel lines of argument, rarely intersecting and relying heavily on fundamentally opposed positions on core principles of bioethics with no reconciliation in sight. That no arguments have 'dropped off' the list testifies to a prevailing inertia. No argument has gained supremacy over others. The same core arguments are cited repeatedly, with only subtle variations, suggesting that a different approach may now be required. Clinical practice has forged on ahead of the discourse and predictive genetic testing in minors has become a reality. ${ }^{57}$ Formal guidelines have evolved to admit some flexibility into considering requests for predictive testing in minors, although they do not provide a framework or criteria to guide this process.

In reviewing the arguments listed in this review, two groups of claims can be identified. A minority are value claims supported by a preordained broader ethical stance, where there is no possibility of empirical investigation. Three (of 33) arguments clearly fit into this category ("testing minors fails to respect their future autonomy', 'testing minors breaches their confidentiality when their results are disclosed to their parents' and 'it is important to avoid professional paternalism'). Of greater interest is the second group of arguments, which are all testable empirical claims that have not yet been tested. Examples of such testable, but so far untested, claims include: 'A positive test result may lead to depression' (1A.5); 'Testing can 


\section{Box 1 A chronology of arguments for and against predictive testing of minors, 1990-2010}

\section{Arguments against testing minors}

1A. Psychological harm for the individual

1A.1 A positive test result may have a negative impact upon self-image and esteem $(1990-2010: 29)^{1}{ }^{5-32}$

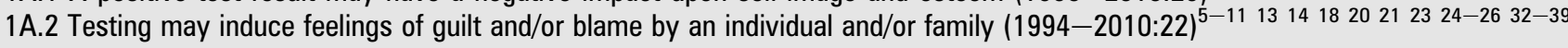

1A.3 An individual testing positive risks stigmatisation by immediate and extended family members

$(1994-2010: 20)^{5} \quad 1113141619-2123-2628303233354041$

1A.4 A positive test result may increase an individual's anxiety (1994-2010:15) $)^{6} 101314182123242630-333842$

1A.5 A positive test result may lead to the development of depression $(2001-2010: 7)^{6} 81320263136$

1 A.6 It is possible that symptoms not due to the condition may be misattributed to early manifestation of the disorder $(1990-2001: 4)^{1} 202743$

1B. Negative effect on family

1B.1 Testing can have a negative effect on family relationships (1990-2010:32) ${ }^{15-7} 9-11$ 13-20 22-27 30-34 36 42 44-47

1B.2 A positive result may lead to modification of parental expectations (vulnerable child syndrome)

$(1994-2010: 14)^{5} 6111218202324263235384547$

1C. Social discrimination and restrictions

1C.1 Discrimination related to insurance (1994-2010:30) 5710 12-15 17 19-24 26-28 31-37 3941454648

1C.2 Social discrimination by peers $\left.(1990-2008: 29)^{1}\right)^{5}-7101113-16 \quad 18-2123-2732-364041444549$

1 C.3 Discrimination related to employment (1994-2008:27) $)^{5} 70-151719-21232426283233-3741454648$

1C.4 Discrimination related to education (1990-2008:13) $)^{16} 1719232426-2832353648$

1C.5 A positive result may restrict an individual's life choices in ways that are out of their control (1990-2010:7) 182426343845

1D. Autonomy

1D.1 Testing minors fails to respect their future autonomy (1990-2010:37) ${ }^{15-9}$ 12-17 19-23 26-36 38 40-43 47485051

1D.2 Testing minors breaches their confidentiality when their results are disclosed to their parents

$(1990-2010: 29)^{1} 5-7912-17192023242627293032-3436384041475051$

1D.3 When testing minors, the risk of information being misunderstood is high (1994-2006:9) ${ }^{5} 14232432-344041$

\section{Arguments in favour of testing minors}

2A. Psychological benefit for the individual

2A.1 Testing may decrease uncertainty for the individual (1990-2010:30) ${ }^{15-7} 911131517-23252629303234353940-424552-54$

2A.2 Testing may decrease anxiety for the individual (1990-2010:17) $)^{15-7} 13161720242529343940444551$

2A.3 Testing can have a positive effect on an individual's identity, self-image and self-esteem

$(2005-2010: 14)^{5} 68911131618192226293652$

2A.4 Testing allows an individual to psychologically prepare for the future $(1997-2010: 11)^{5} 10162627293942455152$

2A.5 There is no evidence of negative psychological consequences of testing (1995-2010:10) ${ }^{6} 91517-20222942$

2A.6 Testing may decrease depression for the individual $(1993-2006: 5)^{5} 1792753$

2B. Positive effect on family

2B.1 Testing may decrease anxiety for the parents $(1990-2010: 23)^{15-7} 13 \quad 15-172024-2729303438-4042444551$

2B.2 Testing may have a positive effect on family relationships (1995-2008:14) $)^{5} 111516182023262734364754$

2B.3 Testing may promote realistic parental expectations of their child $(1998-2008: 4)^{11} 182336$

2C. Planning for the future

2C.1 Testing may enable a family to realistically plan for the future $(1990-2010: 30)^{1} 5-1113-2023-2932364245515254$

2C.2 Testing may inform reproductive decisions for the individual $(1997-2006: 14)^{5} 7101314161719223945515255$

2D. Avoiding/preventing harm

2D.1 Harm could result from not testing $(2001-2010: 8)^{5} 691720263056$

2E. Autonomy

2E.1 Parents are best placed to decide what is in their child's best interest (1994-2010:19) f $^{-10} 1318202426293134363942475153$

2E.2 Adolescents are often capable of making informed decisions about their health (1995-2006:13) 61319222328343539464954

2E.3 Testing may promote an adolescent's autonomy $(2000-2010: 10)^{5} 131619202936404752$

2E.4 Providing a test when the request comes directly from the adolescent can empower that individual to be an active participant in their health $(1998-2010: 7)^{5} 131922 \quad 293947$

2E.5 It is important to avoid professional paternalism (1993-2010:6) 51335425354

have a negative effect on family relationships' (1B.1); 'Testing can decrease uncertainty' (2A.1) and 'Harm could result from not testing' (2D.1). This group of untested claims forms the ethical subtext of the debate over predictive genetic testing in minors. This subtext concerns the ethics of collecting the evidence to settle the question. If most arguments are empirical claims, eminently testable, the matter at hand is whether to test these claims or if the potential outcomes of this research are too harmful to even attempt. Some argue that the harms and benefits of testing should be assessed in empirical research, ${ }^{5}$ while others argue that the potential for harm is too great to ethically conduct this research. ${ }^{46}$

Many of the arguments for and against testing are mirror images of one another. Some authors highlight particular 


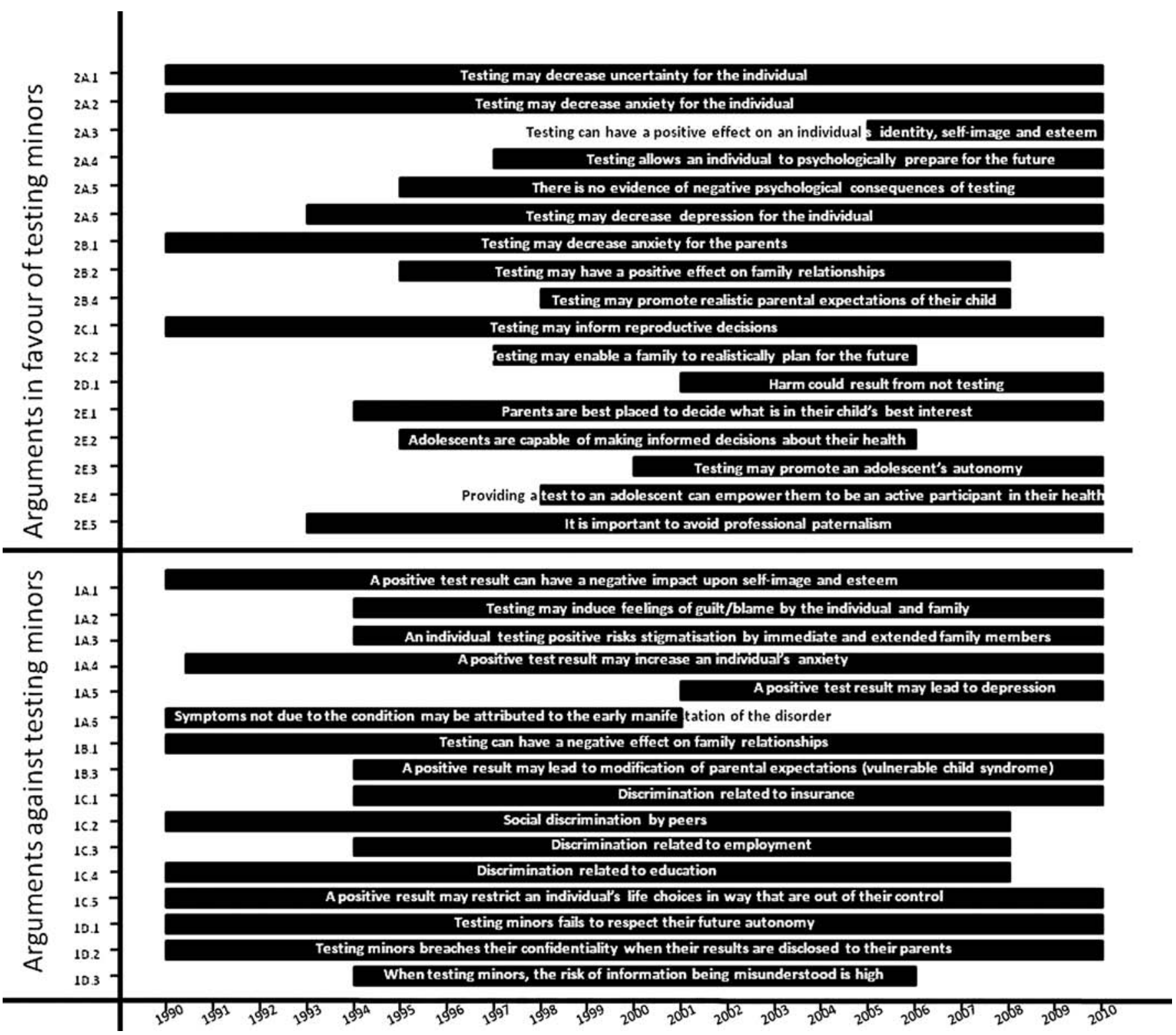

Figure 1 A visual representation of how the debate has evolved over the past two decades. Each black bar represents a discrete argument, indicating the year the argument first appeared in the literature, and the year it was most recently mentioned.

outcomes as net negatives, whereas others look to the benefits associated with these same outcomes. For example, the new knowledge represented by a test result is viewed in negative terms as burdensome or else, more positively, as empowering knowledge enabling future decision-making, thereby promoting autonomy. ${ }^{20}$ There are underlying, mostly unacknowledged, values working to direct the commentators to one or the other interpretation. Working from the same set of ethical principles and concerns (eg, harm, benefit and autonomy), the commentators on either side of the debate have reached opposing conclusions and this sticking point is the position we remain in.

Whereas arguments in favour of predictive genetic testing of minors highlight consequences of receiving both gene-positive and gene-negative results, the arguments against predictive testing have focused heavily on the scenario in which a minor receives a gene-positive test result, largely excluding any serious analysis of potential outcomes. Of the arguments listed above, 11 of 16 assume an unfavourable test result (1A.1, 1A.3-1A.6, 1B.2 and 1C.1-1C.5). Authors appear to believe that the negative ramifications associated with this $50 \%$ probability (a gene-positive test result) are so profound that they outweigh any potential positive impact derived from a gene-negative result. Completely missed from this binary analysis is the possibility that there may be positive ramifications from a genepositive result, or negative impacts from a gene-negative result and, importantly, the potential adverse effects of not testing.

In keeping with the overall lack of systematic work in the area, commentators have rarely discussed which of their arguments specifically apply to infants and younger children, older children or adolescents. A developmental perspective is indispensible, considering each argument as it applies along the trajectory of child and adolescent development. For this review, the authors attempted to categorise each argument by the age group most affected, specifically 'older' minors, 'younger' minors and arguments applicable to all minors. Here, 'younger' minors are 'young people who do not possess the cognitive capacities that allow them to appreciate the implications of predictive testing'. 'Older' minors are considered to have 
developed the capacity to discuss and comprehend, to some meaningful extent, the testing process and potential long-term repercussions associated with testing. Some arguments clearly applied to one developmental stage; however, in most cases, making this distinction was challenging and made it more complicated when the original work of other authors were referred. For example, we felt that argument 1D.2 ('testing minors breaches their confidentiality when their results are disclosed to their parents') related more to younger minors where the request for a test comes from a third party (typically parents) but also acknowledge that some commentators argue that this applies equally for older minors. Ultimately, a developmental stratification was omitted from this review, because there was insufficient raw data, in that the literature to date has not adopted a developmental perspective, generalising, for the most part, across the entire child and adolescent developmental trajectory. Ethical issues vary significantly along the developmental pathway and it is recommended that future work make specific reference to the developmental context for their argument(s) in favour or opposed to predictive testing in minors.

\section{CONCLUSION}

Some novel conclusions can be drawn from this review of the two-decade-long discourse surrounding predictive genetic testing in minors for late-onset conditions where no effective pre-adulthood preventive medical intervention exists. The discourse remains stalled, arguing in theoretical terms over whether the testing is right or wrong, without a clear in principal resolution. One explanation may be that this state of affairs is the consequence of significant and strong moral arguments on both sides of the debate. However, we suggest that the problem arises from the lack of empirical evidence to substantiate either side of the debate. Meanwhile, clinical practice and guidance have evolved to adopt a more flexible patient-centred approach. To date, published work has provided little guidance towards defining an ethical framework for applying this new flexibility. Instead, the opposing positions roll along parallel lines, moving no closer to a critical analysis of the quality of each argument and relying on the same ethical principles of harm, benefit and autonomy to justify their opposing positions.

It is clear that the earliest arguments were opposed to testing and have retained currency, while arguments in favour were initially seen more sporadically and have only gained momentum in recent years. Many of the arguments are mirror images of one another, drawing on core ethical principles but arriving at diametrically opposed positions. Authors arguing against testing have focused heavily on the negative implications of a gene-positive test result and have failed to fully canvass the broad potential benefits and harms of gene-negative or genepositive results, or the potential benefits and harms of not permitting testing. Most of the arguments forming the debate are in fact testable empirical claims, which have not been tested to date. Only a minority are value claims where an ethics discourse is the only means of further exploration. The dispute, therein, lies not so much in whether minors should be permitted to participate in predictive genetic testing but whether these empirical claims on the relative benefits or harms of testing should be assessed. Some authors argue that empirical evidence is required, while others point to a list of potential harms as sufficient to settle the debate and avoid both testing and research into its implications.

There remains an impasse, with little empirical evidence to guide an analysis of the assumptions and values, which underlie many of the arguments made thus far. Many of the arguments against testing highlight potential negative outcomes of testing. There are three possible responses to this situation. The first is to consider the possible negative outcomes of testing to be so onerous that we should remove the possibility of these negative outcomes by completely ceasing the practice of predictive genetic testing in minors. The second is to develop guidelines that allow clinicians to go ahead and make their own clinical and moral decisions based on their judgement in individual cases, and the third possibility is to systematically collect empirical evidence to test the claims regarding negative consequences and reform guidelines based on this evidence. We advocate the latter, which would allow the systematic collection of evidence in controlled and clearly defined settings.

Contributors All the authors have contributed substantially to the manuscript.

Competing interests None.

Provenance and peer review Not commissioned; externally peer reviewed.

\section{REFERENCES}

1. Bloch M, Hayden MR. Opinion: Predictive testing for Huntington disease in childhood: challenges and implications. Am J Hum Genet 1990;46:1-4.

2. Went L. Ethical issues policy statement on Huntington's disease molecular genetics predictive test. International Huntington Association. World Federation of Neurology. J Med Genet 1990;27:34-8.

3. Borry P, Stultiens L, Nys H, et al. Presymptomatic and predictive genetic testing in minors: a systematic review of guidelines and position papers. Clin Genet 2006;70:374-81.

4. Hansen EC. Successful Qualitative Health Research. Sydney: Allen and Unwin, 2006:147.

5. Duncan RE, Delatycki MB. Predictive genetic testing in young people for adult-onset conditions: where is the empirical evidence? Clin Genet 2006:69:8-16; discussion $7-20$.

6. Duncan RE. Predictive genetic testing in young people: when is it appropriate? J Paediatr Child Health 2004;40:593-5.

7. Otlowski M. An exploration of the legal and socio-ethical implications of predictive genetic testing of children. Aust J Fam Law 2004:18:147-69.

8. Pelias M. Genetic testing of children for adult-onset diseases: is testing in the child's best interests? Mt Sinai J Med 2006;73:605-8.

9. Rhodes R. Why test children for adult-onset genetic diseases? Mt Sinai J Med 2006;73:609-16.

10. Sevick MA, Nativio DG, McConnell T. Genetic testing of children for late onset disease. Camb 0 Healthc Ethics 2005;14:47-56.

11. Ross LF, Moon MR. Ethical issues in genetic testing of children. Arch Pediatr Adolesc Med 2000;154:873-9.

12. Fryer A. The Genetic Testing of Children. J R Soc Med 1997;90:419-21.

13. Savulescu J. Predictive genetic testing in children. Med J Aust 2001;175:379-81.

14. Holland J. Should parents be permitted to authorize genetic testing for their children. Fam Law 0 1997;31:321-53.

15. Fryer A. Genetic testing of children. Arch Dis Child 1995;73:97-9

16. McConkie-Rosell A, Spiridigliozzi GA. 'Family Matters': A conceptual framework for genetic testing in children. J Genet Couns 2004;31:9-29.

17. Richards FH. Maturity of judgement in decision making for predictive testing for nontreatable adult-onset neurogenetic conditions: a case against predictive testing of minors. Clin Genet 2006;70:396-401.

18. Malpas PJ. Predictive genetic testing of children for adult-onset diseases and psychological harm. J Med Ethics 2008;34:275-8.

19. Elger BS, Harding TW. Testing adolescents for a hereditary breast cancer gene (BRCA1). Respecting their autonomy is in their best interest. Arch Pediatr Adolesc Med 2000;154:113-19.

20. Robertson S, Savulescu J. Is there a case in favour of predictive genetic testing in young children? Bioethics 2001;15:22-49.

21. Nelson RM, Botkjin JR, Kodish ED, et al. Ethical issues with genetic testing in pediatrics. Pediatrics 2001;107:1451-5.

22. Seeber B, Driscoll DA. Hereditary breast and ovarian cancer syndrome: should we test adolescents? J Paediatr Adolesc Gynecol 2004;17:161-7.

23. Lessick M, Faux S. Implications of genetic testing of children and adolescents. Holist Nurs Pract 1998;12:38-46.

24. Wertz DC, Fanos JH, Reilly PR. Genetic testing for children and adolescents. Who decides? JAMA 1994;272:875-81.

25. Meiser B, Gleeson MA, Tucker KM. Psychological impact of genetic testing for adult-onset disorders: an update for clinicians. Med J Aust 2000;172:126-9.

26. Borry $\mathbf{P}$, Goffin $\mathrm{T}$, Nys $\mathrm{H}$, et al. Predictive genetic testing in minors for adult-onset genetic diseases. Mt Sinai J Med 2008;75:287-96. 
27. Fryer A. Inappropriate genetic testing of children. Arch Dis Child 2000:83 283-5.

28. Cline HS. Genetic testing of children: an issue of ethical and legal concern. Pediatr Nurs 1999;25:61-5, 8

29. Gilbar R. Genetic testing of children for familial cancers: a comparative legal perspective on consent, communication of information and confidentiality. Fam Cancer 2010;9:75-87.

30. Parker M. Genetic testing in children and young people. Fam Cancer 2010;9:15-18

31. Lucassen A, Montgomery J. Predictive genetic testing in children: where are we now? An overview and a UK perspective. Fam Cancer 2010;9:3-7.

32. MacDonald DJ, Lessick M, Julian-Reynier $\mathrm{C}$. Hereditary cancers in children and ethical and psychosocial implications. J Pediatr Nurs 2000;15:217-25.

33. Hanson JW, Thomson EJ. Genetic testing in children: ethical and social points to consider. Pediatr Ann 2000;29:285-92.

34. Patenaude AF. The genetic testing of children for cancer Susceptibility - ethical, legal, and social issues. Behav Sci Law 1996;14:393-410.

35. Hoffmann DE, Wulfsberg EA. Testing children for genetic predispositions: is it in their best interest? J Law Med Ethics 1995;23:331-44.

36. Malpas P. Predictive genetic testing on children and respect for autonomy. Int J Child Right 2005;13:273-85.

37. Quaid KA. Presymptomatic testing for Huntington disease: reply to Sharpe. Am J Med Genet 1994:49:354-6.

38. Clarke A. What is at stake in the predictive genetic testing of children? Fam Cancer 2010;9:19-22.

39. Clayton EW. Genetic testing in children. J Med Philos 1997;22:233-51

40. Twomey JG. Issues in genetic testing of children. Am J Matern Child Nurs 2006:31:156-63.

41. Twomey JG. Genetic testing of children: con uence or collision between parents and professionals? AACN Clin Issues 2002;13:557-66.

42. Fenwick J. Are guidelines for genetic testing of children necessary? Fam Cancer 2010;9:23-5
43. Craufurd D, Donnai D, Kerzin-Storrar L, et al. Testing of children for 'adult' genetic diseases. Lancet 1990;335:1406

44. Harper PS, Clarke A. Should we test children for 'adult' genetic diseases? Lancet 1990;335:1205-6.

45. Stevenson DA, Strasburger VC. Advise or consent? Issues in genetic testing of adolescents. Adolesc Med 2002;13:213-22.

46. Richards F. Letter to the editor in response to Duncan RE and Delatycki MB. Predictive genetic testing in young people for adult-onset conditions: where is the empirical evidence? Clin Genet 2006:69:450-1.

47. Clarke A. Commentary on Duncan and Delatycki, 'Predictive genetic testing in young people for adult onset conditions: where is the empirical evidence?' Clin Genet 2006;69:17-20.

48. Clayton EW. Removing the shadow of the law from the debate about genetic testing of children. Am J Med Genet 1995;57:630-4.

49. Ross LF. Genetic testing in adolescence: is it in their best interest? Arch Pediatr Adolesc Med 2000;154:850-2

50. Binedell J, Soldan JR, Scourfield J, et al. Huntington's disease predictive testing: the case for an assessment approach to requests from adolescents. J Med Genet 1996;33:912-18

51. Ross LF. Should children and adolescents undergo genetic testing? Paediatric Ann 2004;33:762-9.

52. Malpas PJ. Why tell asymptomatic children of their risk of an adult-onset disease in the family but not test them for it? J Med Ethics 2006;32:639-42.

53. Sharpe NF. Presymptomatic testing for Huntingtons disease: is there a duty to tes those under the age of 18 years? Am J Med Genet 1993:46:250-3.

54. Dickenson DL. Can children and young people consent to be tested for adult onset genetic disorders? BMJ 1999;318:1063-6.

55. Burke BM. Genetic testing for children and adolescents. JAMA 1995;273:1089

56. Sharpe NF. Presymptomatic testing for Huntingtons disease: reply to Quaid. J Med Genet 1994:49:355-6.

57. Duncan RE, Savulescu J, Gillam L, et al. An International survey of predictive genetic testing in children for adult onset conditions. Genet Med 2005;7:390-6. 